\title{
Entrevista
}

\section{Una entrevista con José Plácido Ruiz Campillo sobre la gramática operativa y cognitiva y su estado en la enseñanza del español como lengua extranjera}

David Sánchez-Jiménez
NYC College of Technology, CUNY

(Texto recibido 26 de junio del 2017; versión final 28 de junio del 2017; aceptado 05 de Julio de 2017) DOI: https://doi.org/10.5565/rev/jt13.748

\begin{abstract}
José Plácido Ruiz Campillo es profesor titular (Senior Lecturer) en el Department of Latin American and Iberian Cultures de Columbia University en Nueva York. Formado en la Universidad de Granada, donde cursó estudios de máster y doctorado especializados en la enseñanza del español como lengua extranjera, sus publicaciones como pensador y teórico en numerosas revistas especializadas y como creador de materiales didácticos para la enseñanza del español como lengua extranjera (Abanico, El Ventilador, Gramática Básica del Estudiante de Español, Pronombres Personales en la Gramática Básica del Estudiante de Español, Qué Gramática Enseñar, Qué Gramática Aprender) han tenido un eco sin igual en la introducción del enfoque cognitivo y operativo en la enseñanza de la gramática en español. Su repercusión en este ámbito no se limita a su labor investigadora o creativa, sino que se complementa con una profusa colaboración docente en programas de máster impartidos en diferentes universidades, en cursos de formación de profesores en diversos centros del Instituto Cervantes y en prestigiosas instituciones académicas en todo el mundo.
\end{abstract}

\section{Entrevista (junio del 2017)}

Entrevistador: Tras más de 30 años de cambios en la metodología de la enseñanza del español como lengua extranjera, de los cuales usted ha sido cómplice activo, ¿cuál es su estado de salud en la actualidad? ¿Qué hemos ganado y qué hemos perdido en el camino? ¿Hacia dónde se orientan los pasos de la enseñanza de ELE?

José Plácido Ruiz Campillo: Cuando yo empezaba en esto de dar clases de español, la escasez de materiales era tan grande que teníamos que acudir a la adaptación de textos de enseñanza de inglés con el corta, pega y fotocopia de una época todavía en trance de digitalización. Se ha recorrido un largo camino desde entonces. En muchos sentidos, los materiales de enseñanza de español pueden dar hoy lecciones a aquellos míticos de inglés que despertaron nuestra conciencia de la singularidad de esta profesión. Hemos ganado, pues, herramientas, pero con ellas hemos ganado también una diversidad de enfoques tal que prácticamente es imposible que un profesor se sienta incómodo en su tarea, sea cual sea su 
background o su personalidad docente. Hoy en día, a veces para bien y a veces para mal, ser profesor de español es más fácil que nunca.

Entrevistador: ¿Qué papel ha jugado la gramática en esta evolución? ¿Qué supuso la introducción del enfoque cognitivo y operativo en el panorama de la enseñanza de lenguas?

José Plácido Ruiz Campillo: La gramática fue la primera víctima propiciatoria de la revolución comunicativa. Con gran parte de razón, se la envió a la guillotina por formalista y hueca, y se la sustituyó pronto por una visión "comunicativa" de los aspectos formales que consistía, en realidad, en una mera interpretación discursiva y pragmática de los mismos, obviando su significado propiamente gramatical. Después se ha recuperado mucho (yo diría que completamente y de una manera renovada) la preocupación por el lugar de la gramática en el aula, pero en general sigue siendo la gran invitada de piedra que se ofrece troceada y desistematizada como mero auxilio incidental para la "comunicación". En otro lugar he tachado este intento de encaje de la gramática en el programa comunicativo de "falacia metodológica": una visión formalista de la gramática nunca podrá servir de instrumento real a una concepción comunicativa de la lengua, y una descripción funcional (pragmáticodiscursiva) de la lengua no dejará espacio a la lógica en la construcción lingüística. Como el agua y el aceite, forma y comunicación, función y significado gramatical, se repelerán. ¿Qué es necesario, entonces, para dar a la gramática un lugar propio en el proceso? Desde mi punto de vista, una definición radicalmente comunicativa, no de la interpretación discursiva o pragmática de la gramática, sino de la gramática en sí misma. Y eso solo se hace entendiendo, también radicalmente, que la gramática es significado, y opera permanentemente sobre significados.

Entrevistador: Usted es uno de los abanderados de la gramática operativa de base cognitiva que prima la relación de la forma y el significado lingüístico en la gramática con una conceptualización experiencial y visual, ¿en qué consiste esta concepción y qué cambios introduce con respecto a la enseñanza de la gramática tradicional (métodos estructurales) o la no enseñanza de la gramática (enfoques comunicativos)?

José Plácido Ruiz Campillo: Pues como decía, el cambio fundamental proviene del hecho de considerar que la gramática no opera sobre formas, sino sobre significados. Esta idea es 
radical, y de ella se derivan consecuencias radicales, como son el resto de las características de lo que sería un tratamiento cognitivo de la lengua en general, y la gramática en particular, y que exigen una serie de pasos de un lugar viejo a un lugar nuevo. Por ejemplo, el paso de la sintaxis, como explicación formal del enunciado, a la configuración, definida como una "sintaxis del significado". Porque la lógica de la representación lingüística no es una lógica secuencial y proposicional, sino guestáltica. Por ejemplo, la necesidad de sustituir la mera descripción de los usos de la forma por la explicación del camino lógico que hacemos desde el significado de la forma a cada uno de sus usos. Por ejemplo, el abandono del objetivismo en favor de una comprensión experiencialista de la representación lingüística, como tú muy bien apuntabas. Es fundamental reconocer que la lengua no representa objetivamente la realidad, sino percepciones de la realidad, y que éstas están estrictamente sometidas al modo preciso en que la percepción de la realidad opera en nuestra especie. O por ejemplo, la renuncia a tratar la gramática en términos de corrección (¡la palabra "correcto” debería estar prohibida en clase!) para tratarla en términos de eficacia comunicativa: la pregunta no debería ser “¿cuál es la forma correcta?”, debería ser “¿cuál es la forma que expresa lo que tú quieres decir?".

Todo ello con un añadido, importante en mi visión particular del problema, que afecta a la operatividad de la nueva definición: la necesidad de entrenamiento en la capacidad de analizar composicionalmente los productos lingüísticos, o lo que es lo mismo, vencer nuestra inevitable tendencia a interpretar los enunciados de manera holística, confundiendo, a veces catastróficamente, los efectos con las causas. Esta es la única garantía de que esa lógica de la que hablaba antes exista y se mantenga, y por ende, la única manera de ofrecer al estudiante una experiencia de aprendizaje significativo, más que de mera memorización.

Entrevistador: ¿Qué ha aportado la investigación empírica a la enseñanza de lenguas desde un enfoque cognitivo en los últimos años? ¿Cuáles son las posibles líneas de investigación en el futuro en este campo?

José Plácido Ruiz Campillo: Afortunadamente para los que andamos en esto, cada día hay más estudios empíricos sobre la productividad de un enfoque cognitivo en la enseñanza de lenguas, y la dirección en que apuntan es muy esperanzadora. Hay un inmenso campo de investigación en esta línea, desde poner a prueba los efectos de determinadas valoraciones 
gramaticales de naturaleza operativa o cognitiva (vs. estructural o funcional, por ejemplo) hasta investigar el papel de la imagen en la comprensión de la gramática, un tema que siempre me ha parecido apasionante. Hay algunos trabajos sobre esto con resultados positivos, pero personalmente les encuentro el defecto de que no siempre abordan de una definición rigurosa y contrastada de la imagen como representante de valores gramaticales concretos. En todo caso, creo que esta línea de investigación, en un mundo dominado por la imagen, tiene mucho futuro.

Entrevistador: Sobre los materiales didácticos para la enseñanza de ELE que se publican en España actualmente, ¿han sabido adaptarse estas publicaciones al avance producido en la metodología de enseñanza y en la investigación en ELE en las últimas décadas? ¿Se reconoce una incorporación de los principios cognitivos en el planteamiento de la gramática de los manuales de ELE?¿Qué han aportado a la enseñanza del español los materiales didácticos publicados desde la orientación del enfoque cognitivo, como El Ventilador o la Gramática Básica del Estudiante de Español?

José Plácido Ruiz Campillo: Como he dicho anteriormente, el avance en los materiales de enseñanza ha sido tremendo, y hoy en día los profesores de español, junto a numerosos textos de muy dudosa calidad, disponemos de otros muchos a los que se puede sacar muy buen partido en términos, especialmente, de gestión del aula (actividades y tareas, técnicas) y contenidos (en sentido amplio: textos, vocabulario, contextos, etc.). Otra opinión diferente merece, a mi modo de ver, el modo en que en general se trata la gramática, que como digo permanece en general en aquel estadio de taxidermia estructural y/o discursivista en que la encontró la apisonadora comunicativa. Y digo en general porque últimamente veo, tanto en artículos o memorias de máster como en materiales publicados, intentos muy marcados de aproximación a una gestión cognitiva de la gramática, en la línea de la que representa la Gramática Básica del Estudiante de Español. Por poner un ejemplo, en un libro de texto aparecido muy recientemente encontré el otro día una batería de ejercicios de gramática en los que no se pedía la identificación de opciones correctas o incorrectas. En su lugar se ofrecían varias opciones perfectamente correctas y lo que se proponía al estudiante era una interpretación adecuada de cada una de ellas basada en un valor gramatical único de partida. Este pequeño gran salto técnico de lo correcto a lo eficaz y de lo caprichoso a lo lógico es una consecuencia del movimiento de la forma al significado, y es también garantía de un 
tratamiento cognitivo, y a la vez auténticamente comunicativo, de la gramática. Sin embargo, lo que todavía falta, en mi opinión, es una definición más clara y más explícita de los significados gramaticales en términos cognitivos y operacionales. Como dije anteriormente, esta es la forma en que podemos ofrecer al estudiante la posibilidad de una asimilación significativa y lógica de la representación lingüística en español, para que la use en la medida en que le pueda resultar útil.

Entrevistador: Son muchas las voces tenores y sopranos que pregonan la necesidad de llevar al aula una metodología de enseñanza de la gramática basada en el aprendizaje implícito, relegando la enseñanza explícita de la gramática al tratamiento de los elementos fosilizados, ¿qué opinión le merece este juicio?

José Plácido Ruiz Campillo: Cuando un profesor me dice "Eso no se lo explico a mis alumnos porque se hacen un lío" siempre sospecho que el que se hace el lío es el profesor. Y lo sospecho porque soy profesor de español también, y sufro día a día en mis propias carnes la inagotable e inabarcable curiosidad de mis estudiantes por la inagotable e inabarcable complejidad de la gramática de nuestra lengua. Explicar y entender gramática de un modo que no sea superficial y mecánico no es fácil, fundamentalmente porque nunca se nos ha entrenado para ello. Pero eso no nos autoriza a dejar solo al estudiante ante la gramática. Por supuesto, cualquier persona puede aprender una lengua sin profesor o libro de texto, e incluso a pesar de los profesores y los libros de texto (sucede cada día, también en mis clases). Es más: no solo pueden aprender gramática implícitamente, también pueden aprender vocabulario implícitamente, y estrategias conversacionales, y fórmulas de saludo o cortesía, y fiestas populares del Perú. ¿Por qué pensamos que la gramática, seguramente el componente más opaco y sin duda difícil de asimilar y usar de todo esto, le podrá venir sola, y en cambio nos esforzamos por enseñarle, por ejemplo, el vocabulario de la casa o la estructura argumental de un texto? Por supuesto, creo que el profesor, y el material docente, deben intervenir de manera muy directa en el imprescindible proceso de reestructuración (conversión del input desordenado en reglas de producción) que el estudiante debe acometer por sí mismo, y sin darse ni cuenta, para guiarlo en ese proceso con los mejores medios y en la mejor dirección posible. En otras palabras, creo en una enseñanza muy explícita de la gramática. Sin embargo, estaré perfectamente de acuerdo con todo aquel que me diga que la gramática al uso, esa gramática heterogénea (ya oracional, ya discursiva, ya pragmática), 
ilógica y carente de significado, no ayuda en mucho al estudiante en su dominio efectivo de la comunicación en español, y que para ese viaje es casi mejor dejarlo que vaya captando por sí mismo ese sentido comunicativo y esa lógica constructiva que se le niega. Creo que hay que enseñar gramática, pero una gramática de significados, no de formas, una gramática orientada a la eficacia comunicativa y no a la corrección, una gramática lógica y no memorística. La cuestión no es gramática sí o no, es qué gramática y cómo.

Entrevistador: La gramática cognitiva y operativa requiere un mayor esfuerzo intelectual por parte del estudiante con respecto al estudio memorístico de la gramática tradicional. ¿Puede esto suponer un impedimento para la adquisición de la lengua en algunos contextos específicos de enseñanza reglada donde los estudiantes no tienen una alta motivación (por ser esta asignatura un molesto requisito) o una capacidad cognitiva baja para procesar el pensamiento lógico y abstracto, como en los niveles de primaria o secundaria, o en países en los que existe una fuerte convicción en la eficacia del estudio formal de la lengua? ¿Pueden ser estos algunos de los límites impuestos a la aplicación del enfoque cognitivo? ¿Cuáles son los parámetros de adaptación posibles para superar estas barreras?

José Plácido Ruiz Campillo: Sí, la imagen que das se me recuerda mucho a la realidad, aunque la verdadera naturaleza de una aproximación cognitiva está un poco mitificada (o mixtificada). Efectivamente, hablar de psicología, de percepción, de Gestalt, de formas gramaticales que valen una imagen, de estrategias de construcción del significado de las lenguas humanas, todo eso parece que exige un gran esfuerzo intelectual, e incluso puede ser que algunos de ellos se consideren temas simplemente irrelevantes en el aula de lengua (o que dé la impresión de una clase de lengua muy poco ortodoxa). Lo sé, sobre todo, porque encuentro en cada nuevo curso la resistencia inicial de mis propios estudiantes, que llegan con una muy determinada cultura académica y una idea muy clara de en qué consiste una clase de lengua y en qué consiste, concretamente, la gramática de una lengua: reglas sin sentido llenas de excepciones que hay que memorizar para que no te pongan mala nota. Sin embargo, puedo asegurar que si en este deprimente panorama el profesor empieza a sembrar significados, intenciones, reglas extensibles, sesgos psicológicos, universales lingüísticos, economía, imágenes, voluntades de comunicar y responsabilidades en que se incurre al usar una forma, yo te puedo asegurar que los estudiantes están preparados para cambiar su opinión, y su inclinación, en un par de sesiones. Y no es del todo cierto, como se piensa, que una manera 
cognitiva de concebir el hecho lingüístico sea intelectualmente más exigente de lo que resulta posible y rentable. Por supuesto, entender que el "Presente" no es presente, sino una afirmación sobre el presente y el futuro, y que el "Futuro" no significa tiempo futuro, sino que es un modo de predicción sobre el presente o el futuro, es mucho más difícil que entender que el "Futuro" es futuro y el "Presente" presente. La mala noticia es que la regla fácil es falsa, y que si quieres aprender un valor de las formas que sea extensible a todos los usos sin contradicciones constantes, más te vale asumir la regla "difícil". La buena noticia es que entender la explicación "difícil" no es tan difícil como parece en absoluto. Por larga experiencia puedo decir que es mucho más difícil para los profesores que para los estudiantes, seguramente porque los alumnos están mucho más abiertos a la novedad que los profesores (porque casi todo lo que esperan es nuevo) y mucho menos predeterminados por prejuicios lingüísticos que ellos (que casi todo lo que tienen en stock está fuertemente asentado).

Además, tampoco la creencia en que las explicaciones cognitivas exigen un alto nivel de abstracción es completamente cierta. De hecho, la mayoría de las valoraciones cognitivas, y por supuesto la totalidad de las que merece la pena usar en clase, se basan en materiales de extraordinaria transparencia, valga la redundancia, cognitiva: imágenes o composiciones configuracionales de origen visual, lógicas psicológicas y comunicativas que el estudiante despliega cada día, sin saberlo, en su propia lengua, interpretaciones metafóricas de la realidad, diferentes perspectivas de representación de un mismo hecho objetivo, etc. Pero todo esto, lo reconozco, no está en absoluto claro para una inmensa mayoría de los profesionales de la enseñanza y general, ni para los centros e instituciones que la albergan en particular. Lo veo cuando hago talleres para profesores y los asistentes se quedan convencidos del interés de este enfoque, pero desolados por no saber bien cómo llevarlo a sus aulas de manera práctica aplicándolo minuto a minuto. La recomendación más simple y practicable que puedo dar es la siguiente: lee algún libro sobre lingüística cognitiva (cualquier manual de introducción vale), déjate empapar por la bocanada de aire fresco y el tsunami de puro sentido común que destila y, con ese espíritu (basta el espíritu) métete en clase. Verás que los libros empiezan a parecerte descripciones de lenguas extraterrestres y que tanto tú como tus estudiantes sois capaces de activar vuestra sensibilidad lingüística (en cualquier lengua) y empezar a pensar en la gramática como una máquina de gestión de significados a poco que os lo propongáis. El resto de la película puede desarrollarse en la oficina del profesor, llena de otros libros y de papeles para garabatear, o simplemente en el día a día de las clases, que sin saber muy bien 
por qué se mostrarán cada vez un poquito más productivas, un poquito más interesantes y de hecho, y por cierto, mucho más intelectualmente placenteras. Porque no son palabras y frases en negro sobre papeles en blanco lo que se ventilará allí, sino las propias leyes que gobiernan el modo en que los seres humanos representan sus experiencias con el fin de compartirlas.

Entrevistador: Usted aboga por acabar con la polisemia de significados del sistema verbal y propone centrarnos en un solo significado permanente de los elementos gramaticales, ¿se ha hecho un esfuerzo pedagógico suficiente para llegar a esta meta? ¿Cuentan los profesores de español en la actualidad con el conocimiento teórico necesario para llevar a cabo esta labor en las aulas? ¿Poseen los materiales y recursos apropiados para llevarla a cabo? En otras palabras, ¿qué cualidades necesita atesorar un profesor de ELE para desarrollar una enseñanza basada en la gramática operativa y cognitiva de forma efectiva? ¿Están preparados para advenir la tercera gramática aplicada a la "Generación de los niños comprendidos”?

José Plácido Ruiz Campillo: Bueno, por lo que respecta al sistema verbal en concreto sí he intentado hacer bastante: una tesis doctoral y tres artículos recientes intentando explicar cómo un sistema verbal basado en el espacio resuelve los problemas tradicionales de la visión temporal del mismo. Otra cosa es lo que haya conseguido o consiga en el futuro. Precisamente este es un ejemplo de uno de los escenarios que mencionaba anteriormente para los profesionales interesados en esta vía, la opción de acelerar el asunto reflexionando explícitamente sobre una comprensión operativa de la gramática. Considerar mi trabajo en este sentido puede servir, para aquellos imbuidos en el espíritu que también mencionaba antes, como ejemplo -modesto- de qué clase de cambios puede esta perspectiva requerir en la manera tradicional de concebir los valores gramaticales, y sobre todo qué ventajas puede tener en términos de aprendizaje significativo, por la parte del estudiante, e incluso en términos de determinación de contenidos, por la parte del docente. Porque redefinir la gramática en términos cognitivos es algo que cada profesor puede ir haciendo día a día en su clase, pero es algo que a la larga, si se persigue de una manera ordenada, va a afectar al propio sílabo, exigiendo su redefinición. No por casualidad uno de estos artículos, el que publiqué en la revista Nebrija, se subtitula "Seis nuevos temas de gramática del español”. Sí, la redefinición cognitiva del sistema verbal produce nuevos temas de gramática, es decir, cosas que el estudiante debe aprender para un uso adecuado de la lengua meta y que hasta ahora no han 
sido incluidas en ningún programa simplemente porque la definición taxidérmica de la gramática hace imposible saber de su existencia.

Y respondiendo a tu pregunta de si se ha hecho suficiente en este sentido, así en general, creo que no. La razón tiene que ver con la dificultad de la ingeniería inversa necesaria para reducir los valores gramaticales a un solo significado permanente, y esta dificultad tiene a su vez que ver con la dificultad de la ingeniería recta necesaria para justificar técnicamente los usos a partir de ese significado. Como dije anteriormente, la reducción a un solo valor (o el camino en esta dirección) exige un entrenamiento en la capacidad de analizar composicionalmente los productos lingüísticos del que no disponemos por razones, diría yo, de cultura académica. Para la inmensa mayoría de los profesores, la afirmación de que es posible explicar todos los usos del Imperfecto, todos, a partir de un solo significado, es una bravata. Lamentablemente para ellos, y afortunadamente para todos, se puede demostrar que es perfectamente posible. Pero el truco no está tanto en dar con el significado adecuado (generalmente esos significados están ya "descubiertos") como en ser capaz de desbrozar la lógica que lleva sin contradicciones de ese significado a sus usos. Este es el valor principal de lo que yo llamo una gramática operativa.

Entrevistador: En el contexto de la enseñanza reglada del español en Estados Unidos (y en otros países) la lengua se presenta en muchas ocasiones reducida a la presentación de ristras de reglas de gramática y vocabulario que configuran la programación curricular que se lleva al aula en forma de materiales de corte estructural o nocio-funcional. Los profesores formados en metodologías más innovadoras se sienten prisioneros de estas dinámicas. ¿Qué alternativas tiene el profesorado ante este tipo de situaciones no tan anormales como nos gustaría que fueran?

José Plácido Ruiz Campillo: Como he dicho anteriormente, a veces puede bastar hacer tu camino con el "espíritu” de una comprensión cognitiva del hecho lingüístico, sin necesidad de seguir un protocolo riguroso o actuar "oficialmente" como un "cognitivista". Porque ni siquiera creo que tal cosa exista fuera de los circuitos "científicos" de la lingüística de salón, pero también porque por experiencia sé que ese "espíritu" puede bastar para encontrar soluciones aceptables a terribles explicaciones o ejercicios gramaticales que podamos encontrar en nuestro libro o en nuestro centro de trabajo, lo cual, como mínimo, es 
gratificante a un nivel personal. Con esto no estoy abogando por que los profesores limiten el

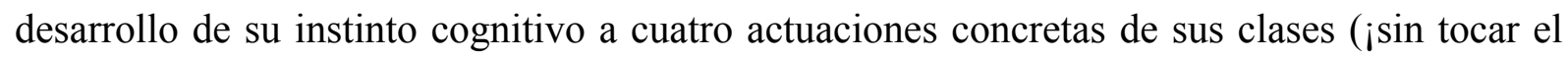
examen!), dando la batalla institucional por perdida. Lo que sí creo es que las instituciones implementan programas gramaticales deficientes porque esos son los programas que la inmensa mayoría de los implicados en esas instituciones tienen en su cabeza, y por tanto la única vía por la que esos programas puedan redefinirse es la de que aumente el número de los profesionales que, como mínimo, se sientan incómodos con esos programas (es lo que yo suelo conceptualizar, con mi habitual poca seriedad, como "salir de Gramatrix"). Y como máximo, que vayan determinando qué tipo de modificaciones, tanto de contenido como de filosofía, podrían mejorar esos programas. Y aquí no abogo tampoco interesadamente por el programa cognitivo-operacional. Al menos no más allá de la medida en que este programa ofrezca soluciones a los problemas existentes, porque esa es la idea: mejorar la calidad de la instrucción gramatical con cualquier medio que demuestre ser capaz de hacerlo. Por supuesto, en mi opinión esta vía es de una extraordinaria utilidad, pero todo programa debe estar permanentemente en vías de modificación y mejora en relación con sus resultados reales por encima de toda agenda ideológica.

Entrevistador: En los Estados Unidos las clases de español como lengua de herencia son una creciente necesidad para aquellos estudiantes que cuentan con estas necesidades específicas de aprendizaje. ¿Qué papel debe jugar la gramática en estos cursos? ¿Se debe aproximar el docente de la misma manera que en una clase de ELE en la enseñanza de la gramática?

José Plácido Ruiz Campillo: El tema de la gramática para nativos siempre me ha parecido extraordinariamente interesante. Mi opinión al respecto es clara: el tipo de gramática que se les administre debe ser la misma, pero el tratamiento debe ser diferente. La primera afirmación, de hecho, es una monumental perogrullada si nos detenemos a pensar que lo lógico sería ponerlos en contacto a todos ellos con la gramática "real", que es una sola, esa que usan los nativos y que difícilmente podemos encontrar en un libro. No lo es tanto si nos damos cuenta de que esa gramática de los libros al uso tiene efectos muy distintos sobre ambos tipos de estudiantes. Una gramática formal, ciega al significado, basada en la corrección y sometida a excepciones constantes podría, con un poco de esfuerzo, ser valorada como parcialmente útil en un determinado estadio de aprendizaje del estudiante extranjero, en la medida en que podría pensarse que le ofrece una "muleta" a la que agarrarse y, aunque sea 
con múltiples errores, permitir la creación tentativa de enunciados a la espera de reestructuraciones que mejoren su factura. Sin embargo, ¿qué le ofrece una gramática de reglas que fallan sistemáticamente en la predicción de las elecciones nativas a un estudiante de español de herencia? Evidentemente, este estudiante no necesita ninguna muleta para disparar su capacidad de tomar decisiones gramaticales: las toma, en general, espontáneamente. Lo que sí necesita es una gramática que refleje lo más fielmente posible lo que hacen los nativos de esa lengua, y lo que hacen los nativos de esa lengua no es ser "correctos", sino ser "eficaces". Porque los nativos no van por ahí acertando para cada "hueco" en su frase la forma correcta entre un conjunto de otras formas incorrectas. Al contrario, para cada "hueco" los nativos eligen una forma correcta entre muchas otras posibilidades igualmente correctas, de acuerdo con un criterio que por lo tanto nada tiene que ver con la corrección, sino con elegir la forma que en cada momento expresa lo que quieren expresar, y no otra cosa. Por diferentes razones, pues, a ambos tipos de estudiantes les convienen reglas gramaticales significativas (basadas en qué se quiere decir) y operativas (que permitan la extensión lógica a los usos). Ahora bien, a la hora de determinar qué gestión didáctica de esta gramática hacer en cada uno de estos casos, es evidente que tiene que ser diferente. La razón es que unos necesitan reglas de operación para abrirse paso en una selva desconocida, mientras que otros necesitan reglas de interpretación para ser conscientes del modo en que se mueven instintivamente por esa selva, y poder así extraer las consecuencias necesarias para seguir explorándola. En todos los casos, se comprenderá que insista, encuentro que una aproximación cognitiva y operacional está en condiciones de ofrecer al mismo tiempo la alta fidelidad en la valoración de los instrumentos gramaticales y la atención permanente al significado que todo trabajo con la lengua con el objetivo de dominarla prácticamente (es decir, comunicativamente) exige. En un caso el camino aconsejable será de la lengua a la comunicación, y en el otro el inverso, de la comunicación a la lengua. En ambos, la gramática debería ser la precisa mecánica del significado que corre de un lado al otro.

\section{Biodata del autor:}

David Sánchez-Jiménez trabaja como Assistant Professor en New York City College of Technology (CUNY), tras haber enseñado en diversas instituciones de España, Filipinas, Hungría y Estados Unidos. Completó su formación académica en la Universidad de Salamanca y en la Universidad Antonio de Nebrija, en la que recibió el Premio Extraordinario de Doctorado del curso 2014-2015. Su investigación se centra en la organización retórica del discurso académico, la interculturalidad retórica y sociopragmática en textos escritos en el ámbito de las segundas lenguas y el aprendizaje de la ortografía en ELE.

Email: dsanchezjimenez@,CityTech.Cuny.Edu

Para citar este artículo: 
Sánchez-Jiménez, D. (2017). Una entrevista con José Plácido Ruiz Campillo sobre la gramática operativa y cognitiva y su estado en la enseñanza del español como lengua extranjera. Bellaterra Journal of Teaching \& Learning Language \& Literature, 10(3), 90-100. DOI: http://doi.org/10.5565/rev/jt13.748

(c) (1) 